\title{
Representações da ação profissional docente: (des)construções via processos de interação linguageiros na trajetória da formação
}

\author{
Vanessa Bianchi Gatto* \\ Marcia Cristina Corrêa**
}

\begin{abstract}
Resumo
Neste artigo, expomos alguns resultados de nosso estudo centrado em diagnosticar as representações sobre o trabalho docente (des)construídas por um aluno de licenciatura ao longo de sua formação. A pesquisa esteve teórica e metodologicamente fundamentada no Interacionismo Sociodiscursivo (ISD) de Bronckart (2012) e de Bronckart e Machado (2004), cuja tese básica é a de que o desenvolvimento dos indivíduos ocorre em atividades sociais, em um ambiente constituído e organizado por diferentes préconstructos, os quais são por eles apropriados e transformados através de processos de mediação, especialmente os linguageiros. Nesse sentido, tomamos como objeto de análise os textos que configuram o discurso desse aluno e materializam suas representações, as quais são por ele construídas e desconstruídas a partir das relações estabelecidas nas experiências concretas de sua formação, especialmente por meio do diálogo com outras vozes. $\mathrm{Na}$ medida em que os resultados da análise dos seus textos apontam para o protagonismo enunciativo em meio a um conflito dialógico, confirmamos a tese do ISD tanto sobre o papel ativo do sujeito quanto sobre a importância dos processos de textualização na transformação de representações socialmente construídas, o que nos leva a apostar no potencial que esses textos podem ter no sentido de possibilitarem a construção endógena (cf. RICHTER, 2008) de um perfil identitário ao profissional docente.

Palavras-chave: Interacionismo sociodiscursivo. Representações. Trabalho docente. Profissionalização.
\end{abstract}

\section{Introdução}

As considerações aqui apresentadas são fruto de um estudo ${ }^{1}$ que visou ao diagnóstico das representações sobre o trabalho docente (des)construídas por um

* Universidade Federal de Santa Maria (UFSM).

** Universidade Federal de Santa Maria (UFSM).

1 GATTO, V. B. Representações do trabalho docente (des)construídas por um aluno de licenciatura. 2015. 215 p. Dissertação (Mestrado em Letras) - Universidade Federal de Santa Maria, Santa Maria, 2015. 
aluno de licenciatura ao longo de sua formação. Na medida em que considerou possível a apreensão de aspectos de uma ação profissional (a docente) por via de construtos linguageiros (representações) que são processo e produto das interações estabelecidas sócio-historicamente por esse sujeito (antes e durante o seu processo de formação profissional), o estudo esteve fundamentado em uma abordagem bastante específica do desenvolvimento humano, qual seja aquela interacionista, do modo como a caracterizaremos em seguida.

Nossa preocupação com a ação profissional docente advém do quadro desfavorável que a envolve, especialmente na conjuntura brasileira, em que, por razões históricas, a docência passou a ser vista não exatamente como um trabalho, mas como uma mera função, exercício de uma vocação, tal como o sacerdócio. Essa analogia, ao passo que entende a aptidão à docência como um "dom", parece ignorar os exaustivos anos de formação científica, didático-pedagógica, por que passam os licenciados, e ainda leva a pensar que, como dom divino gratuitamente recebido, essa aptidão deva ser posta a serviço como um ato de amor, entrega e sacrifício, sem esperar recompensas (especialmente materiais).

Se essa concepção fez certo sentido em alguns momentos da história - como na época em que o ensino era função relegada aos sacerdotes (ou a outros letrados, como os advogados), que iam à casa de seus prestigiados pupilos para levar seus conhecimentos - , hoje, ao ser transposta pelo senso comum a um contexto educacional de complexidade bem diversa, gera paradoxos que conferem à docência um caráter de semiprofissão, de tarefa não especializada que pode, portanto, ser desempenhada por qualquer pessoa.

Tal depreciação parece ter se consolidado no Brasil especialmente após o processo de democratização do ensino, quando a ampliação quantitativa e qualitativa de alunos nas escolas exigiu um recrutamento mais amplo e menos seletivo de professores, ocasionando o rebaixamento salarial e a precariedade das condições de trabalho do professor. Ao se pressuporem a desqualificação profissional, a injusta retribuição salarial e a falta de tempo para a preparação das aulas, o professor foi sendo "considerado, ao longo do tempo, cada vez menos capaz de assumir autonomamente a ação docente" (SOARES, 2001, p. 33). A partir daí, vozes externas (de instituições governamentais, da mídia, de livros didáticos, de "especialistas em educação", de "amigos da escola") passaram a intervir cada vez com mais força sobre essa profissão, que, não gozando da autarquia de uma profissão emancipada e regulamentada (cf. RICHTER, 2008), não teve e ainda não tem predisposição para abafá-las. 
Diante desse contexto profissional adverso, que torna a carreira docente cada vez menos atrativa, tivemos o interesse de investigar: $\mathrm{O}$ que leva alguns jovens a ainda ingressarem em um curso de licenciatura? Que concepção eles, futuros professores, têm sobre o trabalho que vão exercer? Essa concepção se mantém ao longo dos quatro anos de graduação ou é desconstruída e reconstruída de alguma forma?

Ao buscarmos responder a essas questões, esperávamos apreender aspectos característicos não só do trabalho docente em si, mas também do processo de formação por que passam os futuros professores, o que só nos parecia possível por meio da análise de representações materializadas na/pela linguagem. $O$ Interacionismo Sociodiscursivo (ISD, doravante), nesse sentido, tal como proposto por Bronckart (2012) e por Bronckart e Machado (2004), apresentouse-nos como um suporte teórico e metodológico útil e coerente para dar conta de nossas ambições. Em consonância com uma concepção de linguagem baseada na perspectiva interacionista, o ISD concebe as condutas verbais como verdadeiras formas de ação, já que foi principalmente a partir do surgimento e do desenvolvimento da linguagem que o ser humano pôde, ao longo de sua filogenia (e que pode, no decorrer de sua ontogenia), interagir e, assim, "agir" no meio social. Os processos de textualização, mediadores dessas interações, passam a ser, portanto, a porta de acesso às condutas humanas socializadas historicamente.

Em outras palavras, o Interacionismo Sociodiscursivo defende que a apreensão das atividades humanas se faz observando não meramente as ações dos homens, mas, especialmente, o que eles dizem sobre suas ações. $\mathrm{E}$ os textos que eles produzem nessa atividade social (assim como as ações que nela desempenham), ao mesmo tempo em que desvelam as representações que têm acerca dessa atividade, podem contribuir para consolidar ou então transformar não só as representações, mas as próprias condutas. (cf. BRONCKART, 2004 apud MACHADO et al., 2009).

Aderindo a essa perspectiva, o ISD tem se preocupado, nos últimos anos, em analisar o papel central da prática de linguagem (agir discursivo) em situações de trabalho e, mais recentemente, sobretudo no Brasil, em situações de trabalho docente. Nesse último caso, investigam-se as representações do trabalho do professor presentes nos diferentes "textos pertinentes às atividades educacionais". Dependendo do texto que se tome por objeto, estar-se-á imerso em um destes três campos de análise do trabalho: o "trabalho prescrito", quando se analisam 
documentos prescritivos especificadores das tarefas a serem desempenhadas; o "trabalho real", quando se tomam por objeto os textos produzidos pelos próprios professores em situação de trabalho; ou o "trabalho avaliado/interpretado", quando se examinam textos produzidos pelo professor ou por um pesquisador antes e/ou depois da realização da tarefa docente. Inserido neste último campo de pesquisas, nosso estudo quis analisar como o trabalho docente é interpretado por um aluno de licenciatura ao longo de sua formação, isto é, antes do efetivo exercício profissional e, em alguns casos, depois de experiências de docência em situação de estágio.

O que trazemos neste artigo são alguns resultados desse nosso empreendimento, os quais permitem observar a interferência das experiências concretas vividas por esse sujeito e das suas interações com o outro, mediadas pela linguagem, na construção e no desenvolvimento de suas representações sobre o trabalho do professor. Em um primeiro momento, caracterizaremos a perspectiva sociointeracionista teórica e metodológica através da qual o ISD busca explicar o referido processo; em um segundo momento, apresentaremos a metodologia de coleta e de análise de dados utilizada em nosso estudo, para, em seguida, apresentarmos alguns resultados que nos parecem oportunos ao contexto desta publicação; em um terceiro momento, apresentaremos alguns reflexos da não regulamentação da profissão docente sobre esses resultados, especialmente no que tange à exogenia discursiva (cf. RICHTER, 2008); e, nas considerações finais, destacaremos a importância de um interacionismo que, distanciado de uma visão determinística do social sobre o individual, valorize, sobretudo, o papel ativo do sujeito na mudança de concepções cristalizadas pela cultura, de modo a encorajar o protagonismo do professor na reconstrução do perfil identitário do profissional docente.

\section{A perspectiva interacionista do ISD}

O caráter interacionista do ISD manifesta-se desde sua própria base epistemológica, que busca integrar ciências humanas e sociais, já que é uma teoria, ao mesmo tempo, linguística, psicológica e sociológica. É sociológica na medida em que compreende que foi ao longo de um processo histórico de "socialização" que o homem conseguiu elaborar suas formas de agir no mundo; é linguística porque entende que essa socialização foi possível graças especialmente ao 
surgimento e ao desenvolvimento dos "signos"; e é psicológica porque defende o papel fundamental das práticas de linguagem no "desenvolvimento humano", ou seja, seu papel na transformação de organismos humanos em "pessoas" (cf. BRONCKART, 2012, p. 22), com capacidade de conhecer e de agir e com consciência de sua identidade.

Nesse sentido, o ISD nega tanto as correntes behavioristas - que analisavam as condutas humanas com base em questões fisiológicas e condições ambientais, desprezando efeitos mentais - quanto as cognitivistas - que analisavam tais condutas com base exclusivamente nas propriedades neurológicas. Bronckart ${ }^{2}$ ( $\mathrm{p}$. 30 ), acreditando que a psicologia só atingiria seus reais objetivos quando saísse de si mesma, idealizou o ISD como um projeto que pudesse considerar, na análise das condutas humanas, as dimensões sociais e também discursivas que lhes são constitutivas.

Tendo isso em vista, aderiu a uma psicologia interacionista-social, a qual permite abordar o estudo da linguagem em seu aspecto discursivo e/ou textual, já que parte do princípio de que são os textos/discursos que materializam as condutas humanas, sendo eles, portanto, as únicas manifestações empiricamente observáveis das ações de linguagem. O interacionismo social, herdeiro que é da filosofia marxista, defende a historicidade do ser humano e interessa-se pelas condições em que se desenvolvem as formas de organização social, sob o efeito das formas de interação de caráter semiótico. Assim, no intuito de analisar as características estruturais e funcionais dessas organizações sociais e as formas de interação semiótica, lança olhar sobre os processos filogenéticos e ontogenéticos pelos quais os signos sociais são interiorizados pelos organismos humanos, transformando-os em pessoas racionais e conscientes.

É para o enfoque do papel da linguagem na formação da consciência que convergem os três eixos epistemológicos que fazem do ISD uma "ciência do humano". Da psicologia Bronckart tomou essencialmente as ideias de Vigotski (1998; 2000), assumindo plenamente a tese do papel decisivo da internalização dos signos de uma língua na constituição do pensamento consciente. Inserido desde sempre em um ambiente onde as relações interpessoais são mediadas pela linguagem, o ser humano vai aos poucos reconstruindo internamente as operações inicialmente externas: à medida que o ambiente social atribui significados às ações da criança, ela vai se apropriando dessas construções sociais e utilizando-se delas 
para perceber e organizar a realidade à sua volta. A linguagem egocêntrica da criança (em que ela fala em voz alta consigo mesma) representa para Vigotski o estágio de transição das funções interpsíquicas (linguagem exterior, com a função social de comunicar e interagir) para as funções intrapsíquicas (linguagem interior, com a função individual de organizar o pensamento e controlar as próprias ações).

Assim, em oposição tanto ao behaviorismo quanto ao cognitivismo, Vigotski defende que o pensamento autorreflexivo não é resultado das propriedades do próprio corpo, mas "da vida objetiva, em seus aspectos de práxis, de ação e de linguagem" (BRONCKART, 2006, p. 36). Aliando o materialismo de Marx ao viés dialético de Hegel, o autor buscou distanciar-se de uma proposta determinista, de continuidade do "mesmo"; para tanto, propôs um esquema de desenvolvimento ancorado em uma dialética da continuidade e da mudança, a fim de destacar que as funções psicológicas superiores do ser humano não são apenas reflexo das interações com o meio social, mas instrumento para uma contínua transformação do meio e de si mesmo 3 (2008, p. 62).

O que Bronckart não encontrou na psicologia vigotskiana foi a definição de uma unidade de análise capaz de dar conta da natureza do fenômeno acima descrito e de deixar clara a relação entre comunicação, ação e linguagem. Vigotski hesitara entre vários conceitos, como "significado" ou "significação", que poderiam constituir uma unidade entre pensamento e linguagem, mas, para Bronckart, isso ainda não permitia a análise efetiva dos processos por meio dos quais a apropriação dos signos se opera. $\mathrm{O}$ autor considerava necessário, primeiramente, delimitar o que é da ordem do social e o que é da ordem do psicológico, definindo, de forma independente, uma unidade sociológica e uma unidade psicológica; depois, sim, definir uma unidade integradora que atribuísse à linguagem um estatuto relacionado tanto à esfera social quanto à esfera psicológica (cf. BRONCKART, 2012, p. 29). Para tanto, precisou aliar à teoria psicológica de Vigotski teorias sociológicas e linguísticas.

Apesar de retomar do sucessor de Vigotski, Leontiev, a diferenciação entre ação e atividade, foi pelo viés da sociologia, especialmente a habermasiana, que Bronckart conseguiu uma clarificação da linguagem como "agir". Definiu como unidade sociológica a "atividade coletiva" (praticada no contexto de uma formação social) e como unidade psicológica a "ação significante" (desenvolvida especificamente por uma pessoa). O caráter "significante" das ações advém da 
compreensão, assumida também por Habermas, de que a cooperação dos indivíduos em uma atividade é mediada por operações sígnicas. Desde a apropriação do primeiro signo ${ }^{4}$ para a realização de atividades complexas, há a mobilização de representações conscientes e ativas que os agentes particulares construíram na sua relação direta com o mundo e transformaram em representações partilhadas. Para o sociólogo, isso vale não só para o "agir comunicativo", mas para o "agir praxiológico": "qualquer atividade se desenvolve levando-se em consideração determinadas representações ${ }^{5}$ coletivas que se encontram organizadas em três sistemas chamados de mundos ('formais' ou 'representados') - mundo objetivo, mundo social e mundo subjetivo" (BRONCKART, 2008, p. 21) -, cada um dos quais engloba um conjunto de conhecimentos que norteiam as ações dos agentes.

$\mathrm{Se}$, ao fornecer uma abordagem pertinente dos fatos sociais em sua relação com os fatos psicológicos, definindo unidades independentes, a sociologia habermasiana contribuiu para solucionar a primeira lacuna deixada por Vigotski, ela foi, para Bronckart $^{6}$ (p. 25), insuficiente no plano linguístico. Faltava ainda definir uma unidade integradora que atribuísse à linguagem um estatuto relacionado tanto à esfera social quanto à esfera psicológica. Por isso, o autor completa e amplia a abordagem sociológica de Habermas, realçando os fenômenos propriamente linguísticos ali implicados. Nesse sentido, ao lado da unidade sociológica e da unidade psicológica, Bronckart (2012, p. 48) institui como unidade linguística de análise o "texto empírico", termo através do qual busca contemplar o duplo caráter (social e individual) de todo texto. Para o autor, quando um agente produz um texto, ele não só mobiliza conhecimentos sobre o gênero de texto que é o modelo social adaptado para aquela situação comunicativa, mas apresenta seus traços de produtor particular de acordo com a representação particular que tem daquela situação de comunicação, o que faz com que o texto seja um "objeto sempre único"7 (p. 76).

Assim, vemos que, para o ISD, as produções de linguagem devem ser consideradas em sua relação com a atividade humana em geral. Isso leva a delimitar, na unidade sociológica que é a atividade coletiva, ações de linguagem que se manifestam materialmente em textos e congregam as representações de

4 E aqui o signo é encarado exatamente como previsto por Saussure, em sua natureza social, convencional e, portanto, arbitrária.

5 Tanto Habermas quanto Bronckart tomam o conceito de "representação" da teoria geral dos fatos sociais, elaborada por Durkheim.

6 Ibid.

7 Ibid. 
um agente sobre determinado contexto de ação, em seus aspectos físicos, sociais e subjetivos. Nas palavras de Bronckart, “[...] é na prática dos signos organizados em textos que se constroem e se transformam os mundos representados" (2008, p. 27).

Foi na filosofia da linguagem de Volochínov (1981) que Bronckart encontrou um modelo de análise textual coerente com a concepção sociointeracionista de linguagem. Entendendo que os signos são produto dos discursos produzidos em interações sociais, Volochínov (cf. BRONCKART, 2008, p. 76) desenvolve uma abordagem descendente dos fatos linguageiros, que começa pela análise das condições e dos processos de interação social, passa pela observação das formas de enunciação presentes nos textos que semiotizam as interações e, por fim, voltase para a organização dos signos no interior desses textos. Esse modelo reflete o caminho descendente que vai da interação social até a formação do pensamento consciente: este só surge depois da internalização dos signos, a qual só é possível pela interação social.

\section{A relação linguagem/trabalho e o ensino como trabalho}

Como se pode depreender da base teórica do ISD, a linguagem assume um papel central, na medida em que "é ela que organiza, comenta e regula as atividades humanas e é por meio dela que se constrói uma 'memória' dos pré-construídos sociais" (MACHADO, 2009, p. 48). Sendo o texto (oral ou escrito) o instrumento no qual e pelo qual se materializam as representações, interpretações e avaliações dos sujeitos sobre as atividades e ações, as pesquisas do ISD dão especial atenção à sua análise e interpretação, voltando-se, atualmente, para analisar as relações entre o domínio da linguagem e o domínio do agir humano.

O trabalho é um modo de agir dos mais antigos da espécie humana, já que, conforme Bronckart (2006, p. 209), “[...] decorre do surgimento, desde o início da história da humanidade, de formas de organização coletiva destinadas a assegurar a sobrevivência econômica dos membros de um grupo". Após realizar um percurso histórico pelas diferentes concepções pelas quais o trabalho foi compreendido, Machado (2007) situa no século XX os primeiros estudos sobre o trabalho, os quais, ligados ao taylorismo e ao fordismo, visavam à adaptação do trabalhador ao trabalho com vistas à maior produtividade. Após a Segunda Guerra, porém, segundo a autora, a ergonomia de linha francesa passa a questionar esse modelo, 
propondo uma análise preocupada, ao contrário, com a adaptação do trabalho ao trabalhador, este último compreendido em seus aspectos fisiológicos, cognitivos, afetivos e sociais.

Havendo uma gradativa substituição do trabalho material e físico pelo trabalho imaterial, que exigiu dos trabalhadores, dentre outras competências, uma maior habilidade de comunicação, as ciências do trabalho passaram a buscar a ajuda de linguistas para pensar as questões de linguagem, o que levou os próprios linguistas a se interessarem pelo estudo da linguagem em situação de trabalho. Como até a década de 90 essas pesquisas estivessem mais voltadas aos trabalhos produtores de bens materiais, a professora-pesquisadora brasileira Anna Rachel Machado alia-se ao professor-pesquisador Jean-Paul Bronckart, da Universidade de Genebra, para juntos conjecturarem acerca de um trabalho de natureza bastante diversa e bem específica: o trabalho docente.

Embora houvesse inúmeras pesquisas desenvolvidas no Brasil, especialmente a partir da década de 90, acerca das atividades educacionais, Machado (2004) acreditava que não encaravam essas atividades como um trabalho. $\mathrm{O}$ que se viam eram discursos prescritivos e coercitivos vindos de vozes distantes da sala de aula, trazendo uma avaliação negativa do trabalho até então executado pelos professores, provocando neles sentimentos de impotência e estresse. Para a autora, a conjunção dos pressupostos teórico-metodológicos do ISD com os aportes das ciências do trabalho poderia constituir um instrumento adequado para dar conta das particularidades e da complexidade da atividade docente como um trabalho, na medida em que observasse, sob uma perspectiva discursiva, como o trabalho docente é representado nos diferentes textos que circulam na sociedade em geral e na esfera educacional. De acordo com Bronckart e Machado (2004, p. 135), a análise desses textos permitiria "uma nova compreensão sobre o trabalho do professor, tanto em relação a seu agir concreto quanto em relação a alguns dos aspectos das representações que socialmente se constroem sobre ele".

Em busca dessa compreensão, nosso interesse foi o de analisar textos produzidos pela própria classe docente, no intuito de ouvir justamente aqueles cuja voz é constantemente abafada pelos juízos de sistemas externos. Dentro de um contexto bem específico, que é o do processo de formação de professores, interessamo-nos por observar que representações um aluno de licenciatura, a caminho de tornar-se professor, (des)constrói, ao longo de seus quatro anos de formação, acerca da atividade que vai exercer. 


\section{Representações do trabalho docente (des)construídas por um aluno de licenciatura}

Nossa pesquisa vincula-se ao projeto "Representações do Agir Docente", coordenado pela Profa. Dra. Marcia Cristina Corrêa e filiado à linha de pesquisa "Linguagem e Interação" do Programa de Pós-Graduação em Letras da Universidade Federal de Santa Maria. O projeto tem como objetivo geral a análise das representações do trabalho docente que estão presentes nos diferentes textos relativos à atividade educacional (documentos oficiais, material didático, discurso de professores em atuação ou em formação, discurso de alunos, textos que circulam na mídia). Uma das ações empreendidas nesse projeto foi o acompanhamento de uma turma de alunos de Licenciatura em Letras - habilitação em Língua Portuguesa e respectivas Literaturas ${ }^{8}$ - durante todo o percurso de sua graduação, por meio da realização anual de entrevistas semiestruturadas.

Os alunos participantes, em um número inicial de 28 , foram entrevistados em quatro ${ }^{9}$ momentos bem pontuais da graduação: primeiro semestre (período dos primeiros contatos com o curso), terceiro semestre (período anterior à disciplina de Didática e ao estágio), quinto semestre (período posterior à disciplina de Didática, mas anterior ao estágio) e oitavo semestre (período posterior aos estágios). A cada ano, as entrevistas abordavam diferentes pautas e tópicos, de acordo não só com o contexto dos participantes em cada etapa da graduação, mas também com as informações obtidas de cada um na entrevista antecedente. Contudo, como o

8 A escolha por um curso de Letras e pela habilitação em uma língua específica deveu-se meramente ao fato de ser o nosso contexto mais próximo, já que a pesquisa não previu uma problematização do objeto de ensino em si, mas de questões relativas ao trabalho docente em geral. Entendemos que, anterior à ausência de um perfil identitário quer para o educador linguístico quer para o educador matemático, é a ausência de uma identidade para o profissional docente. O trabalho do professor, seja de que área for, já contém, por si só, características que o diferenciam de todos os outros tipos de trabalho. Assim, sem negar que o que caracteriza o trabalho docente é, dentre outros aspectos, o domínio de conhecimentos e competências relativas ao objeto específico de ensino, consideramos fundamental que, antes mesmo de tentar traçar um perfil profissional para o professor de língua portuguesa, por exemplo, busque-se conferir ao trabalho docente em geral uma identidade verdadeiramente profissional, e não meramente vocacional, como lhe conferem vozes não só externas, mas também internas ao sistema docente (lembrando que toda e qualquer licenciatura fornece ao futuro professor, paralelamente aos conhecimentos relativos ao objeto da habilitação específica, bases científicas comuns referentes aos fundamentos da educação, à psicologia educativa, a teorias de ensino-aprendizagem, a abordagens didáticas etc.).

9 Com o sujeito selecionado, acabamos realizando cinco coletas, pois, temendo que a coleta do oitavo semestre não se concretizasse a tempo da elaboração da dissertação mencionada, fizemos uma entrevista no sétimo semestre de curso, no período de transição do sujeito entre a experiência de um estágio e a experiência do outro. Depois, havendo tempo, acabamos realizando uma coleta também no oitavo semestre, quando o sujeito já havia finalizado inclusive o segundo estágio. 
objetivo principal era observar a (des)construção das representações do trabalho docente durante o processo de formação do futuro professor, tópicos relacionados a essa pauta (como "O que é ser professor?") foram mantidos em todas as coletas.

A partir da primeira coleta, os textos foram categorizados tomando por critério aquilo que os alunos apresentavam como "motivação" da escolha por um curso de licenciatura. Seis categorias foram elencadas: não conseguiu ingressar no curso desejado (32\%); tem interesse/gosto pela área de língua ou de literatura (29\%); sempre quis ser professor (21\%); escolheu por eliminação (7\%); teve influência de um professor marcante (7\%); teve influência familiar (4\%).

Ao fim de quatro anos de entrevistas, tinha-se, em texto oral e transcrito, um banco riquíssimo de dados relativos à trajetória de formação de alunos com diferentes motivações e impressões em relação à docência. Eram esses dados que desejávamos de algum modo explorar em nossa pesquisa de mestrado, a fim de observar que representações se (des)construíam sobre o trabalho docente ao longo do processo formativo. Contudo, com o bônus da possibilidade de uma pesquisa longitudinal, vinha o ônus de termos de selecionar apenas um sujeito para o nosso estudo.

Tendo nos chamado a atenção o fato de apenas 6 (seis!) dos 28 alunos terem optado pela licenciatura pelo desejo de serem professores, resolvemos selecionar um sujeito dessa categoria a qual perece estar em vias de extinção. Dentre os 6 alunos, selecionamos, após um olhar mais atento aos textos de cada um, aquele que chamou a atenção justamente por certa discrepância que apresentava em relação não só aos textos dos outros sujeitos dessa categoria, mas também aos textos de todos os outros participantes da pesquisa. Mesmo sem uma análise aprofundada, sobressaíam-se na leitura das representações textualmente construídas por "S14"10 convicções e atitudes enunciativas que não foram vistas nos demais textos e que se afastavam inclusive do tipo de textualização de representações do trabalho docente diagnosticado em pesquisas anteriores. Assim, diante da possibilidade de analisar e interpretar, de um lado, um discurso que pudesse ser representativo do quadro geral dos discursos construídos pelos 28 alunos participantes do estudo e representativo até mesmo dos diagnósticos constantes na literatura acerca do assunto e, de outro lado, um discurso que pudesse revelar algo novo, decidimos pela segunda opção, na ânsia especulativa de uma análise minuciosa dos textos

10 Participante de número 14, o qual, constituindo-se sujeito de nossa pesquisa, passou ser designado "S14", preservando-se o seu anonimato. 
por ele produzidos, a fim de encontrar, na materialidade linguística, reflexos de condições específicas da interação realizada com aquele sujeito sócio-histórico específico $^{11}$.

À luz da abordagem descendente de Volochínov (1981), a análise dos textos construídos por "S14" começou pela descrição do contexto de produção de cada um deles, quando pudemos observar as representações do agente-produtor acerca a) do "contexto físico", em que se definiram o lugar de produção, o momento de produção e os interlocutores e b) do "contexto sociosubjetivo", em que se definiram o lugar social, o papel social que esse lugar estabeleceu para cada um dos enunciadores e o(s) objetivo(s) da interação. Em seguida, os textos foram analisados nos três níveis propostos por Bronckart e Machado (2009). No primeiro, que é o nível organizacional, foram identificados o plano global do texto, os tipos de discurso e as sequências que os constituem e, ainda, os mecanismos de textualização, como os de coesão e de conexão. No segundo nível, enunciativo, atentamos para as marcas de pessoa, os dêiticos de lugar e de espaço, os índices de inserção de vozes, os modalizadores e outras marcas de subjetividade, como os adjetivos. No terceiro e último nível de análise, que é o nível semântico (do agir), os dados levantados nos níveis anteriores foram interpretados, o que permitiu que chegássemos às representações do trabalho docente (des)construídas pelo sujeito.

Depois de uma descrição detalhada do contexto de produção e de análises exaustivas no primeiro e no segundo níveis, a interpretação dos dados trouxe respostas a todas as questões ${ }^{12}$ de pesquisa que nos propomos a responder. Os mecanismos de textualização envolvidos no primeiro nível de análise permitiram chegar (1) aos diferentes actantes, elementos e aspectos do trabalho docente tematizados pelo sujeito entrevistado e ao tipo de agir (pluridimensional) que ele atribui ao professor. Já os mecanismos enunciativos envolvidos no segundo nível

11 Importa esclarecer que não tivemos jamais a intenção de estabelecer comparações valorativas entre os alunos participantes, pois entendemos que, como sujeitos, são historicamente singulares, únicos, insubstituíveis e, por isso, incomparáveis. As representações que cada um mobiliza e a forma como cada um as textualiza dependem tão somente da história particular e das interações sociais (via linguagem) que cada um estabeleceu ao longo de seu desenvolvimento.

12 Como são textualmente organizadas as representações do sujeito sobre o trabalho docente? Sob quais tipos de discurso? Que figuras de ação entram em jogo? Quais actantes, elementos ou aspectos do trabalho docente são tematizados? Que tipo de agir é atribuído ao professor? O que é e o que não é valorizado? Quais as avaliações (julgamentos, opiniões, sentimentos) do sujeito sobre aquilo que ele mesmo enuncia acerca dos diferentes aspectos do trabalho do professor? Que vozes aparecem e sobressaem-se? Como elas são gerenciadas na construção das representações? Quem/o que é colocado na posição de verdadeiro autor do trabalho e quem/o que é apresentado como mero elo ou instrumento de uma ação sobre a qual não é efetivamente responsável? 
permitiram constatar (2) o papel de "ator" que S14 atribui ao professor e ao papel de meros "agentes" que atribui aos alunos, bem como observar (3) a relação de conflito que se estabelece entre a voz do sujeito e as vozes sociais na definição do "que é ser professor".

No terceiro nível, as "figuras de ação", propostas por Bulea (2010) a partir da relação entre os conteúdos temáticos e os tipos de discurso, permitiram interpretar essas três facetas do trabalho docente representado por S14 previstas nos dois níveis anteriores. A primeira faceta desvelou-se pela "ação ocorrência", a qual, por sua vez, ao constituir um modo de configuração do trabalho docente que apresenta elementos, gestos e atos dos actantes envolvidos, permitiu-nos verificar, no discurso interativo de S14, a representação da "complexidade do trabalho do professor". A segunda faceta se revelou na figura "ação acontecimento passado", a qual, compreendendo a narrativa de um agir acidental (experiência sem êxito do segundo estágio) evocado sob o ponto de vista do professor, permitiu visualizarmos, no relato interativo de S14, "o caráter imprevisível e intersubjetivo desse trabalho", que exige que ambas as partes (professor e alunos) cumpram seu papel contratual a fim de que se obtenham os resultados esperados. Por fim, a terceira faceta revelou-se pela "ação definição", a qual, ao tematizar o trabalho do professor como objeto de reflexão, permitiu entrevermos, nos discursos teóricos elaborados por S14, "o potencial vocal de um futuro professor" (o sujeito da pesquisa) em meio ao turbilhão de vozes sociais que emitem juízos de toda ordem à profissão docente e que acabam (por sua força em relação a um sistema sem autarquia) cristalizando representações errôneas sobre o trabalho do professor.

Tendo em vista os limites deste artigo, centrar-nos-emos nesta última faceta, já que ela nos parece exemplar no sentido de revelar como essa interação da voz do sujeito com outras vozes interfere na (des)construção de suas representações sobre a docência, ao longo de seu processo de formação profissional. Esse fenômeno dialógico torna-se ostensivo, no texto de S14, especialmente pelos "índices de inserção de vozes", os quais serão explorados a partir de agora, embora no texto de dissertação de mestrado outros mecanismos enunciativos tenham sido também analisados. 
Vozes em conflito: desconstrução de representações via processos de interação

Embora S14 atribua a si mesmo a responsabilidade pela grande maioria dos enunciados que compõem seus textos, ele explicita, tanto na narração de relatos interativos quanto na exposição de discursos teóricos, vozes tanto de personagens quanto de instâncias sociais. ${ }^{13}$ Em ambos os tipos de discurso, são a presença de verbum dicendi e a presença de discurso indireto que funcionam como os únicos índices de inserção de vozes presentes nos textos, já que, tratando-se de transcrições de um discurso oral, não temos o uso de sinais gráficos, como aspas ${ }^{14}$, travessões nem outras diferentes formatações. Alguns verbos de ação também podem sinalizar a inserção de uma voz se forem verbos que instrumentalizam o dictum, isto é, que indicam ações realizadas por meio de um dizer.

Nas ocorrências de vozes tanto de personagens quanto de instâncias sociais, três aspectos foram predominantes e chamaram de forma especial ${ }^{15}$ a nossa atenção nos relatos interativos e discursos teóricos de S14: 1) a forma explícita de apresentação das vozes; 2) a presença marcante da voz do autor empírico em diálogo confrontante com essas outras vozes; e 3) a superposição da voz do autor empírico sobre as vozes alheias.

A intromissão de vozes externas parece ter sido uma constante na trajetória de S14. Desde o momento de sua escolha pelo Curso de Licenciatura em Letras, tratou-se, além do mais, de vozes contrárias aos desígnios do próprio sujeito. No texto 1, S14 coloca em cena diferentes personagens e grupos sociais (pessoas do convívio social, pais e amigos) cuja voz ele teve de ouvir naquele momento:

Teve gente que disse... ah:: Letras... tu pode mais né... tão ruim ser professor... ah... pelo lado da minha família a/pelo menos os meus pais deram apoio né... mas teve amigos meus que disseram ah:

13 Bronckart define dois tipos de vozes além da "voz do autor": as "vozes de personagens" são aquelas precedentes de seres humanos implicados nos acontecimentos ou ações constitutivos do conteúdo temático de um segmento de texto; já as "vozes sociais" são aquelas precedentes de personagens, grupos ou instituições sociais que não intervêm como agentes no percurso temático de um segmento de texto, mas que são mencionadas como instâncias externas de avaliação de alguns aspectos desse conteúdo (cf. BRONCKART, 2012, p. 327).

14 As normas de transcrição do NURC, que foram nossa referência, preconizam o uso de aspas apenas para o caso de citações literais ou de leitura de textos durante a gravação.

15 Dizemos "especial" porque temos em vista não só o contexto social mais amplo que envolve esse estudo, mas o contexto do projeto em que se insere nossa pesquisa, do qual fazem parte os textos produzidos pelos outros participantes, com os quais os textos de S14 estabelecem contraste. Talvez para a análise de outros gêneros e de outros textos empíricos os três aspectos mencionados sejam encarados como estratégias linguísticas usuais. 
Letras ((depreciação))... faz algum melhor né... ((risos)) disseram $\operatorname{assim}(\mathrm{S} 14$, texto 1$){ }^{16}$

A voz dos pais aparece como a única voz favorável à escolha profissional feita pelo sujeito. A expressão “deram apoio", equivalente ao verbo "apoiaram”, traduz uma ação realizada por meio de um dizer partidário à voz do filho. Os enunciados sob a responsabilidade enunciativa das pessoas em geral e dos amigos (destacados em itálico na citação), porém, desvelam uma representação totalmente desfavorável sobre o curso escolhido por S14: “tão ruim ser professor". O dizer "tu pode mais", além de apontar para a representação que as pessoas tinham de S14 como um sujeito competente, sugere que o Curso de Licenciatura em Letras não demandaria tamanha competência. Apesar das manifestações contrárias, contudo, S14 ingressou no Curso, sobrepondo a sua voz (“[...] eu sempre quis ser professor", texto 1) às vozes sociais.

Ao ingressar no Curso, surgiram outras vozes que poderiam levá-lo a desistir da escolha. No segmento abaixo, os verbos de dizer sinalizam a introdução de uma voz social que está indeterminada (haja vista os verbos em terceira pessoa), mas que, pelo texto e pelo contexto, podemos inferir que seja a voz dos estudantes de Letras que já estavam com sua graduação em andamento quando da chegada de S14:

A literatura do ensino médio me disseram que não é nem um pouco parecida com o que eu vou aprender aqui né... e o português também não porque... gramática eu tô tendo agora... (e só depois) a linguística:: e::... essa parte de... análise sintática por exemplo eu não vou ver mais... o que me contaram né... mas... mesmo assim eu tô feliz... tô gostando (S14, texto 1).

A essa voz social que ressalta as quebras de expectativas e os possíveis problemas do processo de formação contrapõe-se a voz do autor empírico ("eu tô feliz... tô gostando"), que expõe um sentimento e uma avaliação opostos ao que se poderia esperar, o que se comprova pelo uso da conjunção adversativa "mas" e da concessiva "mesmo assim".

Depois, já em sua trajetória dentro do curso, chega o momento do primeiro estágio. Nas primeiras semanas de observação, uma voz social já se manifesta,

16 Nas citações que ilustram os índices de inserção de vozes, usaremos negrito para os sujeitos do dictum, sublinhado para os verbos de dizer ou para os verbos de ações que se realizam por um dictum ou ainda para os verbos de ações que funcionam como uma resposta ao enunciado do interlocutor; e itálico para o próprio dictum, isto é, para aquilo que é dito pela respectiva voz demarcada: o enunciado. 
trazendo novamente uma mensagem pessimista em relação à profissão que S14 estava disposto a seguir: "[...] eu cheguei na escola e uma professora perguntou... se eu ainda não tinha desistido de ser professor... né... daí eu não respondi nada para ela né... claro... e fui lá... e comecei a observar as aulas" (S14, texto 1). É a voz social da professora em exercício, que parece ter uma concepção bastante negativa acerca de sua própria identidade profissional. A voz do autor empírico, que no tempo do fato narrado não verbalizou uma resposta à professora, aparece no relato interativo para contar que, embora não tenha lhe dito nada, foi para a sala de aula e começou as observações. De certa forma, essa reação do personagem estagiário, ao ser narrada por S14, funciona como uma resposta à voz daquela professora, uma voz de protesto do autor empírico em relação à expectativa da professora sobre sua desistência.

Em um único segmento de texto, dentre todas as cinco entrevistas, $\mathrm{S} 14$ revela abalada a sua certeza em relação à escolha pela licenciatura. No texto 2 , quando a entrevistadora pergunta se ele quer ser professor, S14 responde, após uma pausa maior: "por enquanto ainda quero". Ao pedido de explicação da entrevistadora, ele diz: "Ah não sei... porque tem muita gente que::: fica/não digo que fica metendo medo sabe... mas:: quando a gente vai conversar com alguém que já tá... exercendo a profissão... às vezes que tu... te desanima um pouco" (texto 2). É novamente a voz social dos professores em exercício. Apesar do uso da expressão não ilocutória "meter medo", a presença do verbo "conversar" comprova que a ação de "meter medo" é executada por um dictum. Apesar da dúvida que essa voz social conseguiu instaurar sobre a escolha profissional de S14, o fato de ele ter continuado sua caminhada na graduação atesta que sua própria voz é que falou mais alto.

Se na primeira experiência de estágio, ao ter sua certeza sobre a escolha profissional testada por uma professora da escola, S14 já se mostrara convicto de suas intenções como estudante de licenciatura, no segundo estágio mostrouse convicto, como professor, de suas concepções de ensino. Diante da voz de uma instituição social de ensino (a voz da escola, representada pela voz de uma professora), que preconizava o atendimento a um programa específico de ensino, S14 desiste de estagiar na instituição:

[...] eu escolhi o EJA justamente pra não ter que fica/me guiar por aquele padrão do vestibular... porque eu fui numa escola e a primeira coisa que a professora falou é que eles seguiam o programa da 
((nome da comissão responsável pelo vestibular na IES pública em que o sujeito estuda))... dai eu desisti... e fui pro EJA (S14, texto 4).

As únicas vozes com as quais S14 parece concordar ou as quais parece levar em consideração são aquelas advindas dos professores da academia e, na situação de preparação de uma aula, as vozes dos alunos:

[...] a gente tá na metade do curso e é como a professora::..... a ((nome da professora orientadora do estágio)) por exemplo falou... que tu vai/ninguém tá preparado entende... eu vou lá dar aula... vou ter que estudar para ir dar aula... não vai ter um momento certo que tu vai estar preparado para ir dar aula... né eu não posso deixar de fazer estágio agora porque eu não me sinto preparado (S14, texto 3).

[...] eu entreguei o relatório... e a professora disse que eu... por enquanto eu é/sou um dos poucos que tinha conseguido mudar um pouco de visão... sabe... de se colocar na posição professor e de:: pensar sobre a turma... pensar nessa visão diferente (S14, texto 3).

Quando a gente prepara a aula... a gente sempre acaba relembrando alguma dessas teorias... por exemplo... ah... agora a gente tem aula com o professor ((nome do professor)) e ele fala muito do interacionismo... então tu vai preparar uma aula e tu pre/pensa nisso... como preparar essa aula da melhor maneira (S14, texto 4).

[...] pelo que eles [os alunos]... hã: responderam no questionário diagnóstico... eu tentei atender ao que eles queriam... né... eles queriam conhecer mais textos mais... literatura... alguns queriam só passar de anos né pra acabar o ensino médio (S14, texto 4).

No primeiro segmento, vemos que tanto S14 concorda com o que diz a orientadora de estágio que nem cogita adiar a realização dessa etapa da formação. No segundo segmento, S14 não necessariamente concorda com o que disse sobre ele essa mesma professora, mas tanto leva em consideração que utilizou a voz dela para avaliar sua situação de futuro professor. Essa construção textual polifônica acaba funcionando não só como uma forma de polidez, na medida em que evita que o expositor teça elogios sobre si mesmo, mas também como uma estratégia argumentativa, na medida em que confere a responsabilidade pelo que é enunciado a alguém que é autoridade no assunto. A terceira citação desvela o partidarismo de S14 às teorias interacionistas privilegiadas pelo professor da academia, já que o entrevistado mostra levá-las em conta no momento da preparação de suas aulas. 
No último segmento, é a voz dos alunos de S14 que entra em cena. Por meio das respostas a um questionário-diagnóstico aplicado antes da regência, os alunos puderam expor sua voz, dizendo o que esperavam das aulas de Literatura. Ao trazer essa resposta dos alunos para o relato interativo, S14 permite que a entrevistadora tenha acesso aos valores presentes naquela turma e transfere aos alunos parte da responsabilidade sobre a escolha da abordagem de ensino que foi utilizada.

Mas é nos discursos teóricos elaborados por S14 sobre "ser professor" que a explicitação de vozes sociais se nos torna particularmente sedutora. É essa uma das singularidades de textualização desse sujeito, que difere seu texto dos textos dos demais participantes sob os três aspectos já referidos: "explicitação" da voz outra, "diálogo" de sua própria voz com a voz outra e "confirmação" das próprias convicções. Ainda assim, como não poderia deixar de ser, é possível divisar a existência de vozes sociais implícitas, as quais o expositor revela como suas. Vejamos o discurso teórico de S14 na primeira entrevista, feita em 2011, quando ele fala sobre "o que é ser professor":

Ah um trabalho bem difícil né... isso eu concordo com quem me disse... e é uma/deve ser uma/eu acho que é uma profissão muito satisfatória né porque::: sem o professor NINGUÉM vai se formar... tem que ter um professor sempre né... ensino médio... ensino superior... mestrado... doutorado (S14, texto 1).

Embora o expositor não defina quem é o dono da voz defensora de que ser professor é "um trabalho difícil", a voz está manifesta, e o diálogo com a voz do autor empírico imediatamente se estabelece. Desta vez, não há conflito, mas compartilhamento de representações. Após essa primeira definição, S14 ainda elabora uma segunda, por meio de um enunciado cuja responsabilidade atribui a si próprio: “[...] é uma profissão muito satisfatória né porque::: sem o professor NINGUÉM vai se formar... tem que ter um professor sempre né [...]” (texto 1). Nossos conhecimentos acerca do contexto de produção desse enunciado, contudo, autorizam-nos a inferir a existência de uma voz social aí implícita: a voz da mídia, mais especificamente a voz de uma campanha publicitária desenvolvida pelo "Movimento Todos Pela Educação"17 e que foi ao ar em uma emissora televisiva

17 “O 'Todos Pela Educação' é um movimento que congrega sociedade civil, gestores públicos de Educação, iniciativa privada e especialistas com a missão de contribuir para a garantia do direito de todas as crianças e jovens a uma Educação de qualidade até 2022, ano do bicentenário da Independência do Brasil" (cf. consta em seu sítio na web: http://www.todospelaeducacao.org.br/). 
de grande audiência no país justamente no mês de abril de 2011 (vide link do site do movimento, nas referências), mês em que realizamos a entrevista com o sujeito. A campanha teve como slogan "Um bom professor, um bom começo" e tematizou "a valorização do bom professor como questão prioritária para a melhora da qualidade da Educação no país" (cf. consta no site). Foi divulgada em todas as mídias, sendo que na televisiva tinha o formato de um vídeo musicalizado ${ }^{18} \mathrm{com}$ uma canção cuja letra diz:

\begin{abstract}
A base de toda conquista é o professor/A fonte de sabedoria, um bom professor/ Em cada descoberta, cada invenção/ Todo bom começo tem um bom professor/ No trilho de uma ferrovia, (um bom professor!)/ No bisturi da cirurgia, (um bom professor!)/ No tijolo, na olaria, no arranque do motor/ Tudo que se cria tem um bom professor/ No sonho que se realiza, (um bom professor!)/ Cada nova ideia (tem um professor)/ O que se aprende, o que se ensina, (um professor!)/ Uma lição de vida, uma lição de amor/ Na nota de uma partitura, no projeto de arquitetura/ Em toda teoria, tudo que se inicia/ Todo bom começo tem um bom professor/ Tem um bom professor. (Autor e compositor: Max Haetinger)
\end{abstract}

Poder-se-ia cogitar que fazemos uma inferência apressada sobre o diálogo que o discurso de S14 estabelece com a letra dessa canção, se não fosse o caso de essa relação ter se tornado ainda mais próxima na segunda entrevista:

$\mathrm{Eu}$ assim... eu acredito que sem o professor não pode existir as outras profissões né::: porque o médico vai t/um dia teve um professor... o engenheiro também... o advogado também... TODAS as áreas necessitam de um professor né? (S14, texto 2).

$\mathrm{Na}$ terceira entrevista, as vozes sociais voltam a ser não só explicitadas, mas criticadas por S14:

[...] não sei bem certo o que É ser professor... mas ((pausa maior))... ah é uma atividade árdua mas é uma atividade prazerosa... eu acho que é/por enquanto é isso sabe é... ((pausa)) é uma possibilidade que tu tem de:::-- todo mund/por exemplo assim ó... todo mundo tá diz q/ah a educação... no Brasil táa:.: horrivel... não é?... mas é pouca pessoa que sai daqui de dentro e vai lá pra escola dar aula... tem a vontade de sair daqui pra dar aula... mesmo que tu faça pósgraduação tudo... é raro quem vai lá... fica falando daqui mas não

$18 \mathrm{O}$ vídeo também pode ser visualizado no site do Movimento, mais especificamente na página a que este link dá acesso: http://www.todospelaeducacao.org.br/sala-de-imprensa/releases/14837/um-bomprofessor-um-bom-comeco-e-a-nova-campanha-do-movimento-todos-pela-educacao/ 
se coloca no lugar de um professor de escola básica... eu acho que mais/eu tô motivado mais a isso entende... a tentar pelo menos ir lá e fazer alguma coisa (S14, texto 1).

Embora a voz explicitada seja a voz de "todo mundo", podemos inferir, com base na sequência da exposição feita por S14, que se trata da voz social dos graduandos em licenciatura e mesmo dos já licenciados. A voz desses grupos sociais é uma voz de crítica à situação da educação no Brasil. Aqui, S14 cria um embate não com o enunciado da voz alheia (como fizera em outros casos), mas com a própria atitude enunciativa dessa voz, que, segundo lhe parece, é uma atitude enunciativa hipócrita ou, ao menos, incoerente com as suas reais intenções. O operador argumentativo "mas" justamente coloca em oposição aquilo que "todo mundo" diz (que a educação no Brasil está horrível) e aquilo que "todo mundo" faz (que é afastar-se da escola). Ainda que a oração que antecede a inserção da voz social, pela qual S14 iria elaborar uma nova definição, apresente-se truncada (“[ser professor] é uma possibilidade que tu tem de:::--”), podemos concluir, pela voz que o expositor reassume ao final do segmento, que, para S14, ser professor é uma possibilidade para ele, pois tem de "tentar pelo menos ir lá [na escola] e fazer alguma coisa". É isso que S14, contrariamente a "todo mundo", está motivado a fazer.

No texto da última entrevista, voltamos a ter a explicitação de uma voz social. Embora o expositor não nominalize o personagem, o grupo ou a instituição social responsável por essa voz, reconhecemos que é uma representação bastante comum que se tem do trabalho do professor, a qual circula há muito tempo e até hoje em diversas instâncias sociais:

Eu acho que... aquela redução à vocação que... a gente escuta né... talvez ela não seja a mais adequada porque... tu pode ter sim uma facilidade pra trabalhar com essas duas... com língua portuguesa e com a literatura... só que vai além disso né... tu tem todo o contato com o aluno... hã.: tu tem... tu vai... tu vai... TU VAI ser o que vai... o meio que tu vai... o aluno vai ter o contato com o objeto né... então... eu acho que é... é uma tarefa assim muito... é complicada sabe... porque cada ano tu vai ter uma experiencia diferente... cada... no mesmo ano tu vai ter três turmas... cada turma uma experiência diferente (S14, texto 5).

Se não há um verbo de dizer indicando a inserção da voz social, há o verbo "escutar", que pressupõe um dictum. A voz social diz: ser professor é uma 
vocação. A voz do autor empírico diz: essa definição é reducionista e inadequada. A explicação dada pelo expositor revela que, na concepção da docência como uma vocação, está implícita a ideia de "um dom" dado por Deus de presente a determinadas pessoas e que lhes conferiria a plena competência para a docência. $\mathrm{O}$ autor empírico até concorda que algumas pessoas possam ter certa facilidade em relação a uma ou outra área de conhecimento, mas discorda de que isso baste para ser professor, pois os vários tipos de conhecimento que essa tarefa exige tornamna, ao contrário de fácil, "complicada". No segmento em análise, vemos que o diálogo conflitante entre a voz do autor empírico e a voz social já está de tal forma consolidado que se revela em um único e mesmo sintagma: "redução à vocação", e explicita, mais do que nunca, a subordinação da voz social à avaliação da voz do autor empírico.

O que vemos nesses exemplos é apenas uma dentre outras atitudes ${ }^{19}$ enunciativas que diferenciam os textos de S14 dos textos dos demais participantes do estudo. Muitos desses alunos não revelavam a consciência que S14 revela sobre a existência social dessas vozes. Assim, ao invés de uma "blindagem acústica", o que se via em seus próprios discursos era a incorporação de representações advindas do entorno, isto é, a internalização de vozes que são externas ao sistema da profissão docente. Diante do contexto adverso (explicitado na introdução deste artigo) que envolve o trabalho do professor, a militância vocal de S14 "ressoa" para nós de forma bastante significativa, configurando-se como um importante sinal na luta pela emancipação da profissão docente, tal como passamos a expor.

\section{Repercussões das (des)construções para a profissionalização}

Richter $(2008$; 2011) tem se dedicado a compreender, por meio de sua Teoria Holística da Atividade (THA, doravante), o fenômeno da profissionalização docente. Para o autor, algumas das características específicas do trabalho do professor, responsáveis por certos paradoxos que o distinguem de outras profissões, estão diretamente relacionadas à sua não regulamentação e não emancipação.

19 Outra marca específica dos textos de S14 é a representação da docência, desde a primeira entrevista, como um trabalho, concepção que o sujeito foi reafirmando e consolidando ao longo da formação, na medida em que ia comprovando, na prática, a complexidade da atividade docente. "Ser professor", para alguns dos outros participantes, não é um trabalho: "VBG: E tu enxerga a docência como um TRABALHO? Tu vê o professor como um trabalhador? / S21: Ai eu acho que não... é tão humano pra gente enquadrar assim um trabalhador". 
Considerando a possibilidade de interferência de um sistema social sobre o outro, via discurso, a THA opõe sistemas endógenos (autopoiéticos) a sistemas exógenos (alopoiéticos). Profissões regulamentadas e emancipadas constituem sistemas autopoiéticos e endógenos, ou seja, sistemas que, além de se autogerirem, são discursivamente identificados pela voz de profissionais pertencentes ao próprio sistema. Já as profissões não regulamentadas e não emancipadas constituem sistemas alopoiéticos e exógenos, isto é, sistemas regulados por sistemas mais organizados e cujos profissionais têm sua identidade construída discursivamente por vozes exteriores, pertencentes a outros sistemas sociais. Explica-se, assim, a presença daquelas tantas vozes no discurso de S14.

Richter (2008) mostra que a exogenia discursiva dificulta a construção de um perfil identitário para o professor, pois o próprio docente, sem ter um lugar institucional próprio, acaba construindo sua identidade a partir de outros lugares. Acaba, assim, incorporando um discurso que passiviza o papel do professor, que o define em termos de crenças e não de conhecimentos, nivelando profissionais e leigos; um discurso que o caracteriza como aquele que, ao mesmo tempo, sabe e não sabe, pode e não pode; um discurso que atribui a ele a responsabilidade pelos fracassos etc.

$\mathrm{O}$ discurso de $\mathrm{S} 14$ nos pareceu promissor justamente por se afastar de uma internalização passiva das representações do senso comum, já que, ao revelar consciência sobre a existência dessas vozes externas, o sujeito ergue a sua voz de professor e luta contra elas, não admitindo qualquer menosprezo em relação à docência e exaltando-a como um trabalho, como um trabalho complexo, nobre e difícil, que não deve ser reduzido a uma função, semiprofissão, vocação, ou qualquer outra coisa que não seja (perdoe o leitor a repetição) um trabalho. Assim, a relação do aluno de licenciatura com as vozes que internalizam um "discurso do déficit" (cf. RICHTER, 2008) é, na grande maioria das vezes, uma relação de conflito, em que S14 não só deixa bem demarcados os limites enunciativos entre os seus dizeres e os dizeres do outro (em uma tentativa de "isolamento acústico"), mas faz sua voz soar mais alto que a voz adversária, evitando riscos de "contaminação" e interferência e saindo, assim, vencedora.

Para Richter (2008), a construção da identidade feita pelos próprios participantes do sistema (endogenia) garante não apenas a autonomia dos profissionais porque a autonomia só legitima e dá poder de decisão -, mas garante, além do efeito de legitimidade (conduta, atitude), também efeito de verdade (respaldo 
declarativo-conceitual que conquista a confiança do cliente) e ainda efeito de prestígio (valor social agregado à imagem do profissional). Nesse sentido, se encontrarmos, no interior da classe docente, outros discursos imponentes como o de S14 e interessados em lutar pela regulamentação da profissão, será mais fácil chegarmos a um contexto de formação semelhante ao das profissões juridicamente ordenadas, em que os graduandos pautam o roteiro de sua formação "por um grupo organizado (o qual, com seus valores, atitudes, práticas, referências conceituais, aspirações, concretiza, num tempo e lugar, determinado papel) que lhe sirva de referência e alvo de investimento afetivo (isto é, que lhe ancore identificação)"20 (2011, p. 111). Como o autor, acreditamos que, a partir desse novo contexto, poderemos encontrar mais professores e alunos de licenciatura com senso de identidade e autoestima.

\section{Considerações finais}

Embora, evidentemente, o nosso acesso às tomadas de consciência por parte de S14 não tenha sido direto, mas mediado pelos textos que o sujeito construiu, nossa interpretação baseada na análise linguística evidenciou a ocorrência, ao longo dos seus quatro anos de formação, de uma atividade constante de desconstrução e reconstrução de representações acerca do trabalho docente, especialmente a partir do embate entre a voz do sujeito e as vozes sociais. Consideramos que a realização das entrevistas teve um papel importante nessa desconstrução, na medida em que acabou exigindo do sujeito a sistematização de ideias sobre as quais pudesse não ter refletido anteriormente ou sobre as quais nem viesse a refletir.

Os resultados de nossa pesquisa, se comparados com a abordagem vigotskiana do desenvolvimento, parecem-nos oferecer, simultaneamente, uma prova de sua validade e um complemento/prolongamento, visando especificamente ao processo desenvolvimental no adulto. Como destacamos na segunda seção deste artigo, o esquema do desenvolvimento proposto por Vigotski tem um caráter dialético. Apoiado na filosofia hegeliana, o autor entende que o espírito, ao confrontarse com objetos desconhecidos, sintetiza-os e absorve-os, reestruturando-se. Em outras palavras, o pensamento avança cada vez que entra em contato com novos comportamentos (ações, palavras), e assim se constrói um mundo de novas

$20 \mathrm{Id}$. 
representações sociais. O que evidenciamos nos textos produzidos por S14 é um prolongamento/complemento desse esquema, na medida em que constituem macrocortes interpretativos, veiculadores do debate gnosiológico acerca do trabalho docente; debate que o sujeito reconstrói de uma maneira só sua.

Bulea (2010, p. 168) deixa claro que "a gestão da heterogeneidade discursiva está no próprio centro dos processos de desenvolvimento das pessoas”. Desse modo, a alternância de vozes no debate ideológico explicitado por S14 tem grande importância de um ponto de vista propriamente desenvolvimental, contribuindo para a atribuição de novas significações para o que o professor faz e é. Ao trazer para o seu texto diferentes vozes, o sujeito percebe o contraste que estabelecem com as convicções particulares que ele próprio foi construindo ao longo de sua trajetória pessoal. E quanto mais avança em seu processo de formação profissional, mais ele vai evidenciando a necessidade de se reavaliarem determinadas representações acerca do trabalho docente disseminadas pelo senso comum e as quais vão the fazendo cada vez menos sentido, na medida em que ele vivencia, nas experiências de estágio, a complexidade do trabalho do professor.

Em termos de profissionalização docente, chamamos a atenção para a necessidade, por parte dos professores, de um olhar mais crítico sobre o próprio modo como constroem textualmente suas representações acerca do seu trabalho, a fim de observar a partir de que lugar discursivo estão falando, de onde vêm as vozes que põem em jogo na elaboração das representações que têm de si mesmos. Tendo em vista a influência sufocante das vozes vindas de sistemas externos, que emitem juízos desautorizados sobre a ação e a identidade do profissional docente, consideramos fundamental a construção discursiva endógena de um perfil identitário, dos professores para os professores. A conquista de um lugar social começa, a nosso ver, pela demarcação e pela legitimação de um lugar discursivo próprio, para o que já dispomos dos elementos essenciais: natureza sociointerativa, papel ativo, linguagem.

\begin{abstract}
This paper aims at showing results of a study focused on diagnosing the representations about the teaching work (un)built by a student of a teaching degree throughout his process of formation. The research was theoretically and methodologically grounded in Socio-Discursive
\end{abstract}


Interactionism (SDI), coined by Bronckart (2012) and by Bronckart and Machado (2004), whose basic thesis is that the development of individuals occurs in social activities, in an environment composed and organized by different pre-constructs, which are appropriated and transformed by them through mediation, especially of language. In this sense, texts that compose the discourse of the student were taken as object of analysis. These texts materialize his representations, which are constructed and deconstructed by him from the relationships established in the concrete experiences of his education, especially through the dialogue with other voices. As the results of the analysis of his texts point to the enunciative protagonism in a dialogical conflict, we confirm the thesis of SDI, as much about the active role of the subject as about the importance of textualization processes in the transformation of socially constructed representations, which leads us to focus on the potential that these texts can have in order to make the endogenous construction (Richter, 2008) of an identity profile for the teaching profession possible.

Keywords: Socio-Discursive Interactionism. Representations. Teaching work. Professionalization.

\section{Referências}

BRONCKART, Jean-Paul. Atividade de linguagem, discurso e desenvolvimento humano. Organização e tradução de Anna Rachel Machado; Maria de Lourdes Meirelles Matencio et al. Campinas, SP: Mercado de Letras, 2006.

BRONCKART, Jean-Paul. O agir nos discursos: das concepções teóricas às concepções dos trabalhadores. Tradução de Anna Rachel Machado e Maria de Lourdes Meirelles Matencio. Campinas, SP: Mercado de Letras, 2008.

BRONCKART, Jean-Paul. Atividade de linguagem, textos e discursos: por um interacionismo sócio-discursivo. Tradução de Anna Rachel Machado e Péricles Cunha. 2. ed. São Paulo: EDUC, 2012. Original publicado em 1999.

BRONCKART, Jean-Paul; MACHADO, Anna Rachel. Procedimentos de análise de textos sobre o trabalho educacional. In: MACHADO, Anna Rachel (Org.). O ensino como trabalho: uma abordagem discursiva. Londrina: Eduel, 2004. p. 131-163.

BRONCKART, Jean-Paul; MACHADO, Anna Rachel. (Re-)configurações do trabalho do professor construídas nos e pelos textos: a perspectiva metodológica do grupo ALTER-LAEL. In: MACHADO, Anna Rachel et al. (Org.). Linguagem e educação: o trabalho do professor em uma nova perspectiva. Campinas, SP: Mercado de Letras, 2009. p. 31-77. 
BULEA, Ecaterina. Linguagem e efeitos desenvolvimentais da interpretação da atividade. Tradução de Eulália Vera Lúcia Fraga Leurquin e Lena Lúcia Espínola Rodrigues Figueirêdo. Campinas, SP: Mercado de Letras, 2010.

GATTO, Vanessa Bianchi. Representações do trabalho docente (des)construídas por um aluno de licenciatura. 2015. 215 p. Dissertação (Mestrado em Letras) Universidade Federal de Santa Maria, Santa Maria, 2015.

MACHADO, Anna Rachel. Apresentação. In: MACHADO, Anna Rachel (Org.). O ensino como trabalho: uma abordagem discursiva. Londrina: Eduel, 2004, p. vii-xx.

MACHADO, Anna Rachel. Por uma concepção ampliada do trabalho do professor. In: GUIMARÃES, Ana Maria de Mattos; MACHADO, Anna Rachel; COUTINHO, Antónia (Org.). O interacionismo sociodiscursivo: questões epistemológicas e metodológicas. Campinas, SP: Mercado de Letras, 2007. p. 77-97.

MACHADO, Anna Rachel. Colaboração e crítica: possíveis ações do linguista na atividade educacional. In: MACHADO, Anna Rachel e cols. Linguagem e educação: o ensino e a aprendizagem de gêneros textuais. Organizado por Lília Santos Abreu-Tardelli e Vera Lúcia Lopes Cristovão (Org.) Campinas, SP: Mercado de Letras, 2009. p. 43-70.

MACHADO, Anna Rachel et al. Relações entre linguagem e trabalho educacional: novas perspectivas e métodos no quadro do interacionismo sociodiscursivo. In: MACHADO, Anna Rachel et al. (Org.). Linguagem e educação: o trabalho do professor em uma nova perspectiva. Campinas, SP: Mercado de Letras, 2009. p. 15-29.

RICHTER, Marcos Gustavo. Aquisição, representação e atividade. Santa Maria: UFSM, PPGL-Editores, 2008.

RICHTER, Marcos Gustavo. Profissionalização docente segundo a Teoria Holística da Atividade: estudo empregando software de mapeamento semântico. In: LEÃO, Rosaura Albuquerque; MOTTA, Vaima Alves. Linguagem e interação: o ensino em pauta. São Carlos: Pedro \& João Editores, 2011. p. 109-140.

SOARES, Magda Becker. O livro didático como fonte para a história da leitura e da formação do professor-leitor. In: MARINHO, Marildes (Org.). Ler e navegar: espaços e percursos de leitura. Capinas, SP: Mercado de Letras: Associação de Leitura do Brasil - ALB., 2001. p. 31-76

TODOS PELA EDUCAÇÃO. Disponível em: <http://www.todospelaeducacaoorg. br/ sala-de-imprensa/releases/14837/um-bom-professor-um-bom-comeco-e-anova-campanhado-movi mento-todos-pela-educacao $>$. Acesso em: 5 jan. 2015. 
VOLOCHÍNOV, Valentin N. (Bakhtin, M.). Marxismo e filosofia da linguagem. São Paulo: Hucitec, 1981.

VIGOTSKI, Lev Semenovich. A formação social da mente: o desenvolvimento dos processos psicológicos superiores. Organização de Michael Cole et al. Tradução de José Cipolla Neto, Luís Silveira Menna Barreto e Solange Castro Afeche. 6. ed. São Paulo: Martins Fontes, 1998.

VIGOTSKI, Lev Semenovich. A construção do pensamento e da linguagem. Tradução de Paulo Bezerra. São Paulo: Martins Fontes, 2000. 
